Bei einseitig steifem Ellenbogen ist die Indikation für eine Plastik in der Regel nur dann gegeben, wenn der Beruf des Verletzten ein bewegliches Ellenbogengelenk verlangt.

Diese neugebildeten Ellenbogengelenke nach Lexer u. Hass sind aber nicht nur beweglich, sondern oft auch soweit belastbar, $\mathrm{da} B$ die Verletzten wieder Sport betreiben können.

\title{
9. Facialisplastik
}

Film

\section{E. ScHMID-Stuttgart}

Es werden neue, vom Autor entwickelte Techniken zur Palliativoperation bei Facialisparesen zur Darstellung gebracht.

Die Digastricusplastik wird dargestellt. Der M. digastricus wird verwendet, um die Schiefstellung der Unterlippe bei der Mundöffnung zu korrigieren.

Des weiteren wurde die Technik der Verwendung der Kaumuskeln für die Lähmungskorrektur verbessert.

Zum Beispiel wurde die laterale knöcherne Orbitawand durchtrennt und zunächst in einer Voroperation durch eine Siliconeinlage ein Gleitlager gewonnen, durch welches später eine am Muskel fixierte Fascienschlinge zu den Lidern geführt wird. Dadurch werden gleichzeitig die Lider besser an den Bulbus adaptiert.

Durch Ohrknorpelverpflanzungen in die Unter- und Oberlippe wird die Anlagerung der Muskel-Fasoienstreifen wirksamer und vorteilhafter.

Zum Zwecke der Stellungsverbesserung der Oberlippe wird ein abgespaltener Sektor des M. masseter mit dem Corrugator der gesunden Seite durch einen Fascienstreifen verbunden. Zugleich kann eine zusätzliche Verbindung von diesem Muskelsektor zum Mundwinkel hergestellt werden.

Es ergab sich ferner die Möglichkeit, die nicht gelähmte Stirnmuskulatur auf die gelähmte Seite zu verlagern, um ein vollständig gelähmtes Lid in die normale Stellung zu bringen und ihm eine ausreichende Beweglichkeit zurückzugeben.

Es wird ferner gezeigt, daß ein nicht gelähmter M. frontalis direkt zum Tarsus verlagert und mit ihm verbunden werden kann, um ein bewegungsloses Oberlid wieder gebrauchsfähig zu machen.

Es werden Bilder von Orbita-Rekonstruktionen mit Haut-, Schleimhaut- und Knorpeltransplantaten gezeigt.

\section{Konservierung und Transplantation der Schweineleber Film}

\section{T. S. LIE-Bonn}

Für den Transport einer Spenderleber zur klinischen Transplantation ist ein möglichst einfaches Verfahren der Leberkonservierung erstrebenswert. In unseren Versuchen führten wir sie in Form der intermittierenden Schwerkraftperfusion durch. Die Konservierungsdauer betrug bis zu 12 Std. Als Prämedikation erhielten die Tiere Atropin. Zur Narkose wurde Pentobarbitalnatrium in die Ohrvene gespritzt. 